\title{
La idea de Historia en la Historia del Reino de Quito de la América Meridional del jesuita Juan de Velasco
}

\author{
Francisca BARRERA \\ Universidad de Sevilla
}

\section{RESUMEN}

La Historia del reino de Quito de la América Meridional del jesuita Juan de Velasco ha sido una obra continuamente desintegrada en el transcurso de su devenir. Escrita en el año 1798 fue condenada a la incomprensión por no ajustarse a los patrones científicos de la época. El análisis de la obra desde su unidad revela una forma de hacer Historia que, amparada en la tradición historiográfica jesuítica en las Indias occidentales, definen un modo particular de ser y de sentir asociado con una identidad criolla diferenciada respecto de los sujetos indígenas y peninsulares.

Palabras clave: Juan de Velasco, historia natural, Reino de Quito, criollismos, mito.

The idea of History in the History of the Kingdom of Quito of the South America of the Jesuit Juan de Velasco

\begin{abstract}
The Jesuit Juan de Velasco's History of the kingdom of Quito of South America has been a continually disintegrated work in the course of his development. Written in the year 1798 it was condemned to the incomprehension because the incapacity to adjuste to the scientific standards of the time. The analysis from it's unity reveals a way to do History that, protected in the Historiographical Jesuitical tradition the West Indies, they defined a particular way of being and feeling associated to a creole differentiates identity about the indigenous and peninsular subjects.
\end{abstract}

Keywords: Juan de Velasco, Natural History, Kingdom of Quito, Criollismos, Myth.

SUMARIO: 1. Historia y Filosofía. 2. Estructura de la Historia. 3. Historia Natural: estructura y método. 4. Conclusiones. 
La Historia del Reino de Quito de la América Meridional 1 del jesuita riobambeño Juan de Velasco, escrita durante el exilio en el año 1789, es un texto que comúnmente ha sido designado como fuente histórica (Herrera 1890, Barrera 1920, Batallas 1927, Jouanem 1940, Espinosa y Tobar 1960 y Larrea 1988, entre otros). Aceptando esta clasificación que es ciertamente lícita, no descartamos la posibilidad de otros enfoques tan válidos como el enfoque histórico. Un estudio de la cultura hispanoamericana y de sus mecanismos transculturadores exige una mirada interdisciplinar que recoja los escritos coloniales desde las especificidades y conflictos del mundo americano. De ahí la necesidad de recuperar las producciones dieciochescas y en este caso, la obra del abate Velasco, como manifestación de un particular modo de ser y de sentir, considerado por algunos la primera expresión de una conciencia pre nacional ${ }^{2}$. Para este caso, la obra del jesuita ecuatoriano será valorada como un conjunto de noticias, tradiciones, costumbres e historias representativas del grupo criollo que formaron parte del devenir cultural, pero que no necesariamente actuaron como un prerrequisito para el nacionalismo ${ }^{3}$. Si bien la historia cultural se interrelaciona con la historia política del continente a lo largo de toda la tradición hispanoamericana, no se puede atribuir a los jesuitas expulsos una intención nacionalista, ya que apartaría sus obras del contexto religioso de la Compañía de Jesús para introducirlas forzosamente en el caudal de la Historia de los nacionalismos en hispanoamericana ${ }^{4}$. Lo que sí podemos afirmar es que muchas de sus obras fueron utilizadas con fines emancipatorios ${ }^{5}$, lo que produjo un desplazamiento de los textos hacia la esfera de la independencia política.

${ }^{1}$ Para este análisis se ha utilizado la edición de la Casa de la Cultura Ecuatoriana de 1977 y 1978 que incluye la correspondencia entre Velasco y el Ministro Polier, así como los dictámenes de la Academia de Historia y las correcciones que fueron realizadas a la obra.

${ }^{2}$ Véase Eileen Willingham, “Locating Utopia: Promise and Patria in Juan de Velasco's Historia del Reino de Quito", en Luis Millones Figueroa y Domingo Ledezma, pp. 250-276, y Silvia Navia Méndez-Bonito, "Reivindicación del reino de Quito en la Historia del Reino de Quito de Juan de Velasco", en Sosa, Buchholz, Ximena y F. Waters, William (comp.). Estudios Ecuatorianos, un aporte a la discusión. Ponencias Escogidas del II Encuentro de la Sección de Estudios Ecuatorianos LASA. Quito: Abya-Yala, 2004, pp. 167-184.

${ }^{3}$ En este sentido, coincidimos con los estudios de Miguel Batllori. El abate Viscardo: historia y mito de la intervención de los jesuitas en la independencia de Hispanoamérica. Madrid: Mapfre, 1995.

${ }^{4}$ El caso del Abate Viscardo puede ser considerado como un caso paradigmático y está lejos de considerarse una norma común entre los miembros expulsos de la Compañía de Jesús.

${ }^{5}$ El 19 de enero de 1792, en el periódico "Primicias de la cultura de Quito", el precursor de la independencia americana, Eugenio de Santa Cruz y Espejo señalaba al pueblo quiteño que la patria ya tiene Historia, la que acaba de escribir el jesuita Juan de Velasco y que sería 
Esclarecidas estas cuestiones, proponemos una aproximación a la obra de Velasco desde una perspectiva literaria, siguiendo los nuevos enfoques de la literatura colonial hispanoamericana con el fin de reflexionar sobre un concepto de Historia que subyace en la producción del abate y en las formas de construcción de una Historia para el Reino de Quito en la segunda mitad del siglo XVIII. En este sentido, consideramos tres aspectos: en primer lugar los paratextos ${ }^{6}$, para identificar cuál es la función que cumple la obra según el criterio de Velasco y cuál es el objetivo que se propone al escribir una Historia desde el plano filosófico. A continuación estableceremos la unidad de la obra a través de la relación entre la Historia Natural, la Historia Antigua y la Historia Moderna. La restitución de la estructura general del texto revelará la visión particular del mundo desde la tradición jesuítica. Finalmente, nos centraremos en la Historia Natural y definiremos su estructura interna y la correlación entre sus divisiones, para terminar con el análisis acerca del método de investigación que utiliza Velasco. De tal manera, la unidad entre estos subcapítulos se puede resumir de la siguiente manera: propósitos, estructura y método. A partir de estos tres elementos daremos un bosquejo acerca de la idea de Historia en el texto de Juan de Velasco, sin fragmentar ni descontextualizar innecesariamente la obra utilizando los criterios contemporáneos.

\section{Historia y Filosofía}

El primer tomo de la Historia del Reino de Quito tenía como primer paratexto la dedicatoria dirigida al secretario de Estado Don Antonio Porlier en la que Velasco alababa los méritos de éste funcionario de Carlos IV: "Admira con razón sus talentos la Monarquía toda. Salamanca, aquella fecunda madre de las artes, y de las ciencias, lo aplauden en la primera época de su floreciente edad, coronando con laureles que supo cortar con su diestra mano en las Palestras de Minerva..." (Velasco, 1977: 18). Una de las virtudes que el jesuita destacaba en Porlier era su "rectitud de justicia" ya que "pesando con imparcial balanza" podía ser "no sólo protector,

traducida al italiano por los padre Larrea. Véase Velasco, p. 485. Así también, en la carta que Francisco de Miranda dirige al Ministro Pitt el 20 de marzo de 1798 anexa la "Vista Política de la América Española", texto que se basa en la Historia Antigua de México del jesuita Francisco Xavier Clavijero: “...en sólo en Reyno de México, nos dice el Jesuíta Clavigéro, nuestro compatrióta escritor de la Moderna Historia de México (en respuesta á las noticias que se pidiéron como hombre tan instruído en la materia)..." (Francisco de Miranda. América Espera. Caracas: Ayacucho, 1982, pp. 211-212).

${ }^{6}$ Considerando las aportaciones de Gerard Genette en Palimpsestos. En este caso entenderemos por paratexto el título, subtítulo, intertítulos, prefacios, epílogos, advertencias, prólogos y todos aquellos elementos que se relacionan con la obra en su conjunto. Véase Gerard Genette. Palimpsestos. Madrid: Taurus, 1989. 
sino también científico juez de su causa" (refiriéndose a la veracidad de la Historia). Juan de Velasco solicitaba el amparo de la autoridad con el fin de ver publicada la mayor de sus obras, cuyo trabajo buscaba por recompensa "la satisfacción de mostrar mi pronta obediencia al Orden Soberano, con dar este pequeño testimonio del amor que conservo a la Patria, y del respecto que debo a la persona de Vuestra Excelencia" (Velasco, 1977: 19). Este paratexto inicial establecía en términos generales los motivos para formar una Historia de la nación, aunque su verdadero fin era asegurar la publicación de los manuscritos a través del patrocinio de una de las autoridades de la Corona española ${ }^{7}$.

En segundo paratexto que corresponde al prefacio de la obra, que no se salvó de las acotaciones de la Real Academia de Historia ${ }^{8}$, el abate expresaba la necesidad de

${ }^{7}$ Antonio Porlier realizó sus estudios en la Universidad de Salamanca durante el reinado de Felipe V hasta su muerte en 1746. Los monarcas posteriores apreciaron la figura de este ilustrado y le otorgaron variados cargos. Felipe VI lo nombró en 1757 Fiscal Protector de Indios. En 1765, bajo el reinado de Carlos III, se le otorgó el cargo de Oidor de la Audiencia de Charcas. Dos años después ejerció como Fiscal de la Lima y en 1773 se desempeñó como Fiscal del Consejo de Indias. A su regreso a Madrid, el rey le nombró miembro de la Cámara de Indias. En 1787 lo designaron Ministro de Despacho de Gracia y Justicia de Indias. Durante esos años creó el Jardín Botánico de Tenerife. Bajo el reinado de Carlos IV obtuvo los mayores cargos y honores: Consejero de Estado, en 1789; Ministro de Gracia y Justicia en Indias, en 1790; Marqués de Bajamar, en 1791; Gran Cruz de la Orden de Carlos III, en 1792. Cuando cae Floridablanca, Carlos IV lo nombró Gobernador del Consejo de Indias. Véase Marcos Guimera Peraza, "Don Antonio Porlier, Marqués de Bajamar (17221813)", Anuario de Estudios Atlánticos, no 27 (1981), pp. 113-115.

${ }^{8}$ Algunas de las acotaciones de la Real Academia de Historia: cambiar la palabra "indianos" por "indios", "abastecido" por "instruido", "desviados sistemas" por "extraños sistemas" (a propósitos de los métodos de los antiamericanistas). El resto de las correcciones se aplicaban a ciertas palabras que podrían considerarse más correctas para expresar una idea de acuerdo a la norma académica, pero no se trataba de hechos significativos. En el primer caso, indiano significa "nativo, pero no originario de América" (según la RAE), lo cual sustentaba la teoría de Velasco en la que el hombre había pasado del Antiguo Mundo a Nuevo Continente a través de diferentes medios migratorios. La Academia corrigió esta palabra por la de "indio" que significa indígena de las tierras americanas que desciende de los primitivos habitantes sin mezcla de raza. En este sentido, los censores utilizaban un término que aludía directamente al habitante autóctono, sin confundir con aquel que nacía de la unión entre español e india y de paso excluían de la significación una teoría se extendía a la naturaleza del hombre americano y a su lugar en el mundo. La segunda modificación era un intento por borrar el contexto del exilio. Velasco realizaba una crítica implícita al destierro que lo obligó a separarse de sus materiales de estudio, por lo tanto, no estaba "abastecido" para la labor. En vez de eso, los académicos optaban por "instruido", modificando así la idea general de la frase. Por último, corrección bajaba el tono polémico al prefacio y lo desligaba un poco de la carga religiosa que intentaba hacer patente Velasco con la palabra "desviado". 
escribir una Historia particular del Reino de Quito por "haber salido a la luz, en estos tiempos, no pocas Historias generales y particulares de la América" (Velasco, 1977: 21) . Ésta fue redactada "por cumplimiento del Orden Soberano" (Velasco, 1977: 17), como señalaba en el texto dedicatorio, pero también por "persona que podía mandarme" y por "varios amigos con repetidas instancias" (Velasco, 1977: 21). La orden de escribir una Historia para el territorio de Quito le había sido dada antes de partir al exilio, por lo que varias de sus investigaciones se realizaron mediante el contacto directo con los objetos narrados ${ }^{10}$. Sin embargo, una vez establecido en Faenza, narrar una Historia de Quito, tenía como fin supremo "hacer un corto servicio a la Nación y a la Patria" ${ }^{11}$ (Velasco, 1977: 23). Inicialmente, su Historia tendría cuatro o cinco tomos gruesos:

[...] así para anotar las equivocaciones y errores de los escritores antiguos, como principalmente para refutar las calumnias, falsedades y errores de algunos escritores modernos, especialmente extranjeros. Este ímprobo trabajo que debía ocupar la mitad de la obra, lo omitiré casi del todo, así por la brevedad, como porque lo han hecho ya otras bien cortadas plumas. (Velasco, 1977: 23)

Atento al momento histórico desde el cual narraba y consciente de su delicado estado de salud, el abate decidió reducir el contenido general de la obra y hacer "unas cortas refutaciones cuando las juzgare más necesarias" (Velasco, 1977: 23) con el fin de ver publicada su obra y dar a conocer el Reino de Quito a la comunidad europea.

${ }^{9}$ Antes de la Historia de Velasco, el jesuita riobambeño Pedro Mercado (1618-1701) escribió la Historia de la Provincia del Nuevo Reino y de Quito de la Compañía de Jesús, sin embargo, no fue publicada sino tardíamente en 1957. También existieron otras historias que hablaron sobre el reino, pero sin considerarlo como una unidad cultural diferenciada y específica, ya que lo relacionaban con los límites de los reinos coloniales. Entre ellas, podemos nombrar la Historia de la Conquista y de la Población de Venezuela de José Oviedo y Baños (1723). Historia General de las Conquistas del Nuevo Reino de Granada, de Lucas Fernández de Piedrahíta (1688) y el Libro Primero de las genealogías del Nuevo Reino de Granada de Juan Flores de Ocádiz (1674). Con esto, podemos advertir que el trabajo de Velasco no sólo era necesario, sino además original. Véase Santos, p. 343 y Colección Virtual Biblioteca Nacional.

${ }^{10}$ No existen datos concretos que puedan avalar que Velasco hubiera rescatado durante el exilio sus apuntes sobre la Historia de Quito, sin embargo, la lógica y la razón permiten pensar que de alguna manera logró salvar sus observaciones sobre el Reino y que no escribió de memoria, como afirman algunos de sus detractores.

${ }^{11}$ Además de servir como referencia a la labor desempeñada por la Compañía de Jesús, motivo por el cual recibió el primer mandado para escribir una Historia de Quito de parte de uno de sus superiores. 
El segundo paratexto tenía como función determinar los fundamentos que impulsaron su obra y además situar el texto dentro de una tradición historiográfica específica. Para ello, Velasco oponía dos tipos de historiadores, el "crítico y filósofo a la moda" y el "filósofo y crítico verdadero". El primer caso aludía sin duda a las obras de Paw, Raynal, Marmontel, Buffón y Robertson:

La elocuencia, y el engañoso esplendor, con que escriben aquellos célebres literatos han llegado a deslumbrar varios ingenios para que suscriban tanto más incautos, cuanto más ciegos sus desviados sistemas. De aquí es, que formada una moderna secta de filósofos anti-Americanos, se hablan, y se escriben, con suma autoridad, y libertad, los más solemnes desatinos. Más qué importa? Todo imparcial, de cualquier Nación que sea, no descubrirá en sus obras, sino el lamentable abuso de sus talentos. Verá con evidencia que unas no han tenido otro impulso que el de seguir el capricho de una filosofía desenfrenada: otra, que el de sembrar doctrinas erróneas, y peligrosas: otras que el meter en odio común contra la nación conquistadora, y otras que el sembrar en sus conquistas la irreligión, y la anarquía. (Velasco, 1977: 23)

Para el abate, estos científicos no buscaban un conocimiento real de América, sino que por el contrario, sólo deseaban degradarla y adaptarla a sus teorías. La filosofía que representaban era ilegítima, oscurecía la realidad con sus forzados sistemas y no estaba contenida en el principio fundamental de toda la ciencia: la verdad. Sumado a lo anterior, el "filósofo a la moda" se desviaba de la verdadera fe, no consideraba la creación como símbolo de la divinidad suprema y, como señalaba Velasco, ponía en duda la luz del día y los fundamentos más sólidos de la humana y aún divina fe (Velasco, 1977: 22).

En el segundo caso, el "filósofo y crítico verdadero", era, en palabras del abate, capaz de conocer las causas y los efectos naturales de los objetos que describía y además podía discernir en el confuso caos de las antigüedades lo maravilloso y lo real. Todas estas cualidades correspondían a los filósofos cuya visión progresista de la Historia buscaba un equilibrio entre el predominio de la razón humana y la experiencia. La indagación en la verdad contribuía para ellos al crecimiento humano, combatiendo así la ignorancia, la superstición y el abuso de poder.

Dentro de este panorama cabe preguntarse ¿cuál era la línea de pensamiento en la que Velasco inscribía su Historia? Uno de los motivos por los cuales el jesuita no deseaba escribir la historia de Quito era su incapacidad para discernir entre lo fabuloso, lo cierto, dudoso y lo probable (Velasco, 1977: 22)... es aquí entonces donde la experiencia americana incide directamente en el lugar de enunciación del sujeto. Desde esta perspectiva, Velasco se presentaba a sí mismo como un ser afectado por la experiencia criolla, testigo de hechos prodigiosos que sólo podían aclararse a partir de una visión del mundo más allá del sistema causa efecto que desarrollaban los filósofos de la Ilustración. 
Con esta clara conciencia de la diferencia colonial (Mignolo, 2000), el jesuita creaba su propia concepción de Historia y la ponía en relación con la labor de historiador dentro de la tradición historiográfica de la Orden. Velasco no podía desligarse de un conocimiento experimentado que lo situaba más allá de lo racional (en la tradición indígena, en lo fabuloso, en el milagro), pero tampoco quería dar a entender ese hecho como parte de una falta a la verdad. El filósofo ilustrado discernía entre lo real y lo maravilloso, mientras que Velasco, amparado en una tradición jesuítica de Historias, registraba en cada hecho, prodigioso o no, una verdad moral inserta en el plano de la creación divina. Esta concepción del conocimiento sujeta a una ética religiosa se presentó desde la obra de Acosta en adelante para toda la tradición de Historias escritas en el Nuevo Mundo por los miembros de la Compañía de Jesús. Aquella verdad ontológica estaba, así mismo, relacionada con un lugar de enunciación imparcial o si se prefiere con un grado cero de la escritura cuyo espacio debía ser ocupado legítimamente por un nuevo actor en el mundo colonial:

Si el historiador debe ser imparcial, para no cargar los vivos colores de una parte, y las negras sombras de otra, vicio, a que si el Patricio se inclina por el innato amor a la Patria, propende mucho más el extranjero, por la general antipatía de las Naciones yo, ni soy Europeo por haber nacido en América, ni soy americano, siendo por todos lados originario de Europa; y así puedo más fácilmente contenerme en el justo equilibrio que me han dictado siempre la razón y la justicia. (Velasco, 1977: 22)

Pese a la aparente imparcialidad del jesuita ¿podría, acaso, comprobar la existencia de los Scyris, de los zoophytos o de algunos vegetales con características maravillosas? Quizás no desde una filosofía ilustrada europea, pero sí desde la experiencia criolla que integraba las coordenadas del mundo indígena a un saber propio y particular sobre el Nuevo Mundo. Lo anterior no implicaba un abandono por parte de Velasco de los métodos científicos del Siglo de las Luces, sino más bien una puesta en crisis respecto del alcance de estos sistemas europeos de conocimiento en el espacio americano.

\section{Estructura de la Historia}

Los tres tomos de la Historia del Reino de Quito fueron remitidos al Secretario de Estado entre los meses de marzo y junio de 1789. En la correspondencia establecida entre Velasco y Porlier, éste señalaba en reiteradas ocasiones la unidad de su obra:

Aunque me esforzaba a no perder momento por concluir con mi obra, me hallaba muy acobardado, por ignorar el éxito que podría tener en ella [...] Mas con la favorecida de V.E. de 15 de Mayo próximo pasado, he cobrado tanto vigor y aliento que me parecen nada el tormento de los ojos, la sordera total, males de cabeza, y 
mil otros trabajos, incomodidades y miserias con que vivo. En la tercera y última parte de la Historia, la cual saldrá necesariamente más larga que las precedentes... (Velasco, 1977: 29)

En la última que recibí de V.E. de 30 de Junio pasado veo la suma dignación, con que se ha servido favorecerme, no puedo dar mejor respuesta que la adjunta remisión del tercero y último Tomo de la Historia... (Velasco, 1977:30)

Así también, en la dedicatoria expresaba "al tiempo de recibir el segundo orden, de parte del Augusto sucesor, Nuestro Soberano, que Dios guarde concluyo puntualmente con la segunda parte de la misma Historia" (Velasco, 1977: 17).

Como es posible advertir, el abate siempre habló de una Historia y no de tres Historias independientes entre sí. Sin ir más lejos, el título de su obra anunciaba lo que era, una Historia del Reino de Quito de la América Meridional. Aunque los tres tomos fueron remitidos por separado, esto no justificaba las divisiones, rupturas y fragmentaciones que se hicieron a lo largo del tiempo ${ }^{12}$.

Como señalamos, el mismo título sugiere la estructura unitaria de la obra, sin embargo, los tomos proponen una división temática en tres partes: Historia Natural, Historia Antigua e Historia Moderna. La Historia Natural estaba compuesta por cuatro libros. También incluía un apéndice en el que hacía una crítica a la obra del jesuita, Felipe Salvador Gili, Historia de tierra firme (1780-1784), más un "Catálogo de algunos escritores antiguos y modernos del Perú y Quito". Por último adjuntaba una carta geográfica del Reino y su extensión. Los libros I, II y III presentaban como tema a la naturaleza desde su geografía, hasta los componentes del reino vegetal y animal. El Libro IV se extendía hacia el reino racional, es decir, hacia el hombre americano "vindicado de la moderna filosofía" (Velasco, 1977: 255). En este capítulo, Velasco presentaba sus teorías acerca del poblamiento de América y exponía los supuestos orígenes del pueblo quiteño, así como el carácter moral y físico. Estas ideas las alternaba con las refutaciones y reparos que hacía de las teorías antiamericanistas de Buffon, De Pauw y Robertson. La relación entre los libros I, II y III y el libro IV se puede resumir a grandes rasgos como la unión del hombre

${ }^{12}$ La primera división de la obra fue realizada por la Real Academia de Historia. Según el dictamen firmado por Campomanes y los 19 miembros del tribunal de censura, los tomos de la historia antigua y moderna eran dignos de ver la luz pública una vez que se corrigiesen los puntos señalados, lamentablemente "no podemos decir lo mismo de la parte que comprende la Historia Natural, que, sin embargo de los nombres científicos que hemos añadido al margen de varios animales y plantas, queda muy imperfecta e inexacta en las descripciones, y convendrá darle otro título o calificación, como vg. Repertorio o Manual de noticias y nombres vulgares pertenecientes a las producciones naturales del Reino de Quito" (Velasco, 1977: 46). Posteriormente la historia de la obra de Velasco sufriría modificaciones y rupturas en las ediciones de Ternaux Compans (1840 y1841), Agustín Yerovi (1841, 1842 y 1844), Pólit (1946), Toscano (1953) y Pareja Díez Caseno (1981). 
con la naturaleza, en cuanto a creación divina, y la manera en que ésta lo determinaba. Sin embargo, a diferencia de los animales y gracias a la disposición de un Dios creador, su reino era el de la razón. La relación entre los libros I, II, III y IV va de lo menos perfecto a lo más perfecto, siguiendo a Acosta, y consistía en una gradación ascendente, a partir la cual el ser humano se encontraba en el punto más alto. Este aspecto era una continuación de la doctrina Aristotélica de las almas, que distinguía el alma vegetativa o nutritiva (general a las plantas, animales y a los hombres), del alma sensitiva (que corresponde a los animales y a los seres humanos) y del alma racional (exclusiva de los hombres). En síntesis, el Tomo I situaba a la naturaleza americana desde una perspectiva cristiana del mundo, uniendo sus elementos en un plan de creación divino y delineaba la humanidad del indígena y su participación en una historia providencial.

La Historia Antigua del Reino de Quito estaba compuesta de cinco libros. Los Libros I, II y III correspondían a los distintos reinados anteriores a la llegada de los españoles a América (Fundación del Reino por los Quitus, Reinado de Hauynacapac y por último Reinado de Atahualpa). El libro IV o "cuarta época de la antigüedad" narraba la conquista de los españoles desde su llegada en 1533 hasta el comienzo de las guerras civiles. Un segundo periodo para la conquista se presentaba en el libro $\mathrm{V}$, en el que se describían nuevas invasiones y fundaciones en los gobiernos de Gonzalo Pizarro y Vaca de Castro. Así también se hacía alusión a las batallas contra los indígenas y a las revoluciones de los españoles hasta el regreso de Pedro de la Gasca a España, luego de reordenar la administración del Virreinato.

La Historia Moderna comenzaba con la llegada de una época de relativa tranquilidad que permitía el establecimiento de las colonias. Este último Tomo de la Historia estaba compuesto por cinco libros los cuales trataban sobre la "Descripción histórica, geográfica, política y eclesiástica del Reino de Quito". El libro I describía las provincias de Popayán, el libro II "Las provincias altas del Quito propio, que componen el Gobierno de Quito" 13 , el libro III "Las provincias bajas del Quito propio que componen cuatro Gobiernos", el libro IV "Las provincias orientales del Quito impropio que componen cinco Gobiernos" y finalmente el libro V lo dedicaba a las "Provincias del Marañón y sus misiones, que componen un solo y dilatado Gobierno". La Historia Moderna finalizaba con la expulsión de los jesuitas de los reinos ultramarinos de Carlos III en 1767.

Acosta dividió los mundos en la esfera de lo natural y lo moral, siendo la clave de esta división interna el libre albedrío del ser humano, es decir, la capacidad de los hombres de crear los mecanismos de su propia cultura. Por su parte, Velasco continuaba esta tradición basándose en la idea de un mundo en el cual el hombre se ceñía tanto a la naturaleza como a la civilización. Al finalizar la Historia Natural

${ }^{13}$ El "Quito propio" de Velasco es el territorio del Reino anterior a la llegada de los españoles, es decir, el Quito de las comunidades indígenas. 
quedaba establecida la posición de los indígenas al interior del mundo cristiano: América no era un continente fuera de la providencia divina, había formado parte del diluvio universal, había recibido previamente a la llegada de los españoles el evangelio a través de los apóstoles Santo Tomás y San Bartolomé, contaba con una naturaleza sana, habitable y generosa. El hombre nativo no era un degenerado como suponían los "naturalistas de gabinete", provenía de una cultura antigua y además estaba ligado a las tradiciones incas. Desde el punto de vista natural, el hombre dejaba de estar condicionado a las teorías de los filósofos de moda:

Si hubiese de seguir yo el humor de algunos filósofos modernos, podría excusar enteramente este 4 y último Libro de la Natural Historia. Según ellos no tuvo la América Reyno Racional. Se hallaron sí, por todas partes, ciertos animales bípedes o sátiros, que hablaban, y tenían tal cual apariencia de hombres; mas con vestigios tan equívocos sobre su racionalidad, que excitaron grandes dudas, y disputas sobre sí eran, o no de la estirpe del primer hombre. (Velasco, 1977: 225)

De tal forma, la Historia Natural cumplía la función de establecer las bases para una cultura que sería desarrollada más ampliamente en la Historia Antigua. Como señalaba Velasco en la introducción del IV Libro del Tomo I:

Casi todo lo que puede decirse de los habitadores del Reyno de Quito, pertenece, a la Historia Antigua, o Moderna de ellos. Por lo tocante a la Natural Historia, bastaría señalar su distintivo carácter en lo físico y moral. Más como este tiene tanta relación, y conexión con su misma Historia, no puede hablarse de aquel sin tocar muchas veces esta. Por otra parte, no pudiendo decir las propiedades de un hombre, sin suponer quien es, o de dónde trae su origen me parece este lugar más propio para tratar la primera población de aquellas partes del mundo, y descender después a la particular del Reyno. Apuntaré sobre cada duda o punto controvertido [...] La decisión de estas mismas controversias, servirá de preámbulo, o más bien de Primer Libro a la Antigua Historia del Reyno. (Velasco, 1977: 256)

El abate Velasco desarrollaba una continuidad natural entre el reino racional en su naturaleza y en su cultura, pues como él mismo señalaba, no se podía hablar del carácter de una persona, sin considerar su origen. Por este motivo era trascendental descartar el nacimiento del hombre americano fuera de la cultura occidental dominante. De ahí que Velasco sostuviera que el poblamiento del Nuevo Mundo se realizó a través de procesos migratorios posteriores a la revelación de Dios a los hombres, como el diluvio universal o la confusión de las lenguas en Babel.

La Historia Antigua proporcionaba las bases culturales del mundo quiteño y mostraba el estado alcanzado por los indígenas en su máximo desarrollo educativo y de gobierno. No obstante, el grado de perfeccionamiento de las culturas prehispánicas tenía como límite el desconocimiento del evangelio. Sólo a través de la cristianización podían superar el estadio en el que se encontraban. De esta forma, la 
Historia Antigua adquiría sentido en la medida en que se unía a la Historia de la cristiandad. Este modo de otorgar una razón de ser a las civilizaciones antiguas en coherencia con la Historia ortodoxa, se inició con la bipartición del padre Acosta entre la Historia Natural y la Historia Moral. Sin embargo, la Historia del Reino de Quito no era sólo Antigua, sino también Moderna. El abate reivindicaba el origen del Reino cuando lo describía como una civilización cuya Historia no se desvanecía en la conquista española, sino que por el contrario, constituía parte de su devenir.

La Historia Antigua llegaba hasta el año de 1550, fecha que cerraba el periodo de conquista y abría un espacio de relativa calma. La Historia Moderna era la Historia de la evangelización en el marco político colonial. Los territorios de la Real Audiencia de Quito eran reconocidos desde lo propio (como ya señalamos, anterior a la colonización española) e impropios (atribuidos por las conquistas). Dichos espacios se vinculaban a la labor de la Compañía de Jesús, con la fundación de sus colegios, misiones y casas. En "Sobre lo que ha florecido la ciudad de Quito en ciencias, artes y virtudes" del Libro I, Velasco señalaba:

Los primeros 53 años después que se establecieron los españoles en la ciudad de Quito, pueden llamarse sin agravio, los años de ignorancia. Verdad es que, desde el principio, se fundaron en ella diversos Ordenes de Regulares y que tuvieron grandes conventos. Entre ellos hubo sin duda no pocos hombres doctos; mas estos no estaban en proporción ni circunstancia de enseñar al público las letras. Las únicas que se estudiaban privadamente y por muy pocos eran algo de latinidad y de moral, en aquel grado preciso para ordenarse de sacerdotes.

Los primeros Estudios Mayores que se vieron en el Reyno fueron los que establecieron los Jesuitas en la Cuidad de Quito. Fueron pedidos y llamados con grande instancia y con la oferta de una pingüe fundación de un colegio, desde que los primeros, mandados por San Francisco de Borja, llegaron al Perú, en el año 1568. (Velasco, 1978: 318)

Para el jesuita riobambeño, la Historia Moderna era el establecimiento de las provincias de la mano con la labor educativa jesuítica. En el prefacio del Tomo III, Velasco mostraba su intención para la Historia y con ello dotaba de significación su obra:

Mi intento es apuntar solamente los principales hechos y sucesos más notables de que puedo dar noticia [...] y siendo necesario hacer una breve descripción de las Provincia del Reyno, según el estado presente de ellas, tomo el medio de no seguir más orden que el de misma descripción. De esta suerte, hablando de cada una de las provincias diré los sucesos principales que le perteneces, con la particular cronología que le fuera posible. Solo así podrá verse con claridad y sin fastidiosas interrupciones lo que cada una fue en sus principios, en los tiempos medios y en el presente. Más con decir en el tiempo presente no entiendo yo hasta el año en que escribo, sino solo hasta 1767. (Velasco, 1977: 247-248) 
Para recapitular, La Historia Natural era la base para hablar de la dignidad del entorno americano y de sus habitantes. La Historia Antigua otorgaba legitimidad a la Patria criolla y continuidad a la Historia del Reino, es decir, el mito fundacional se unía al conjunto de sucesos de la conquista en una relación de sentido. Finalmente, la conquista estaba vacía de significado sin la presencia de la evangelización. La Historia Moderna comenzaba con el establecimiento de la Compañía de Jesús y terminaba con su expulsión, cerrando de esta manera la Historia del Reino de Quito de la América Meridional. Vemos así cómo el sistema de ideas que fundamentaba la Historia se basaba en una visión religiosa que abarcaba la creación del mundo: el cosmos, los montes y los ríos, hasta llegar al hombre, para luego buscar en él la historia de una cultura destinada a ser cristianizada por la nación española, pero más aun por los miembros de la Orden de Ignacio de Loyola.

\section{Historia Natural: estructura y método}

El análisis de la Historia Natural nos remite al conjunto de premisas en las que se basó la obra de Velasco. En el libro I se describían los cuatro elementos de la naturaleza ${ }^{14}$ siguiendo la tradición escolástica y jesuítica que adoptaba las enseñanzas de la antigua filosofía griega, en este caso, la teoría de Empédocles reformulada por Aristóteles ${ }^{15}$. Esta división le permitía al jesuita estructurar su primer Libro tratando de los aspectos relativos a los cuatro elementos: aire, fuego, agua y tierra. Así el capítulo 1 atendía a los vientos, temperatura y clima en general, el capítulo 2 a los volcanes. Del capítulo 3 al 8 se ocupaba de los ríos, mares y lagos y el capítulo 9 lo dedicaba a la riqueza de los montes o reino mineral. Una vez finalizados los temas del mundo simple, pasaba a los elementos compuestos y los reducía a tres categorías que correspondían al reino mineral, vegetal y animal. Los libros I, II y III, se dedicaban a estos temas en el mismo orden. El libro IV distinguía al ser humano como parte del reino racional. La estructura general del texto correspondía al pensamiento griego, específicamente al que planteaba Aristóteles. Fue el estagirita quien recogió el sistema de los elementos simples y compuestos y los incorporó a

\footnotetext{
14 "Libro I: Situación, estructura, materiales, clima, montes, ríos, lagos, mares, puertos, islas". Véase Juan Velasco. Historia del Reyno de Quito. Tomo I. 1977 [1789], índice.

${ }^{15}$ Este filósofo materialista de la antigua Grecia, en su poema filosófico «De la Naturaleza», reducía toda la diversidad de las cosas a cuatro «raíces»: tierra, agua, aire y fuego. Como se sabe, esta teoría de los cuatro, elementos (o «principios» de la naturaleza) se mantuvo en la filosofía antigua y medieval durante muchos siglos. Cfr. Rosental e Iudin. Diccionario Soviético de Filosofía. Montevideo: Puebla, p.136. Aristóteles llamó a la teoría de las "cuatro raíces", "cuatro elementos". Esta última denominación es la que utiliza Velasco para el Libro I.
} 
su idea sobre las almas nutritiva, sensitiva y racional (plantas, animales y hombres). El orden que invocaba Velasco era el mismo que planteaba Aristóteles, ya que iba en una escala ascendente en grado de perfección. La jerarquía que utilizaba el jesuita, siguiendo con la tradición de Historias Naturales de la Compañía, dejaba al hombre el lugar más alto en la esfera de la Creación. El ser humano se constituía como parte del mundo animal, sin embargo, su esencia racional lo hacía superior al resto del mundo viviente:

Los vivientes sensitivos se dividen en Racionales, e Irracionales: aquellos, a cuyo imperio sujetó el Autor de la Naturaleza a éstos; y éstos a los cuales destinó para el servicio, para la comodidad, para el sustento, y aún para la diversión de aquellos. Siendo los hombres los únicos que por superior naturaleza componen la primera clase de vivientes, ocuparán el $4^{\circ}$, y último Libro de la Historia. (Velasco, 1977: 169)

Siguiendo la tradición pliniana otorgaba a cada reino una utilidad en el mundo, de tal manera hacía referencia a "algunos vegetales útiles para la medicina", "modos de pescar" y "frutas comestibles de plantas y árboles", así como "de algunos vegetales que parecen maravillosos, por sus efectos de difícil inteligencia" o "Monstruos", integrándolos en un beneficio común que podía estar tanto en lo práctico como en lo trascendental. Así, lo maravilloso o fantástico compartía esta característica.

Pese a la evidente influencia de los clásicos en el pensamiento de la Orden de Loyola, la orientación científica del siglo XVIII también dejó huellas en la obra de Velasco. En este sentido, remitirse sólo a la filosofía Aristotélica resultaría limitado e incompleto. La naturaleza americana favorecía la reformulación de las antiguas concepciones teóricas y su actualización. Al respecto, vamos a esbozar dos elementos que podrían indicar la influencia de las ideas ilustradas en Velasco: el espíritu crítico y la primacía de la experiencia. Lo más curioso es que, al parecer, ninguno de estos dos aspectos se resuelve en un saber científico y moderno.

La división de los elementos de la naturaleza estaba precedida por la delimitación del territorio. De ahí que el sistema Aristotélico cumpliera una función distinta en la literatura dieciochesca hispanoamericana. Cuando se acotaba el espacio que se iba a narrar, el primer aspecto (o elemento) que se trataba era el clima. Como señala Navia Méndez-Bonito (2004), esto era una estrategia defensiva contra las ideas de los antiamericanistas que proponían una degeneración total del entorno americano a través de la insalubridad del clima “...este clima, así entendido, aunque diverso, es generalmente sano y favorable..." (Velasco, 1977: 55).

En la misma línea, podríamos referirnos a las teorías acerca de la invariabilidad de las especies propuestas desde Aristóteles en adelante y seguidas en la Edad Media por la filosofía escolástica. En la segunda mitad del siglo XVIII la taxonomía de Linneo había sido ampliamente difundida. El mundo científico ilustrado aceptaba esta clasificación y su nomenclatura. Algunos jesuitas también adoptaban el sistema 
linneano en sus historias de la naturaleza y se esforzaban por mostrar un conocimiento actualizado de las ciencias ${ }^{16}$. Por otra parte, el mismo concepto de especie, la universalización de la nomenclatura científica y la variabilidad de los animales eran temas que enriquecían el ambiente intelectual. Sin embargo, Velasco presentaba en su obra una particular forma de concebir el universo, recogiendo las fórmulas nuevas, no sin antes someterlas a un examen sobre la aplicabilidad de ellas al mundo criollo. Para el jesuita, las especies eran variables, podían cambiar con el tiempo, cruzarse entre ellas y dar cabida a otras especies. Sólo este hecho explicaba que en América hubiese animales que nunca se habían visto y que no estaban incluidos en las clasificaciones de Plinio. Según la teoría aristotélica platónica, las especies tenían esencias inmutables, mientras que en las clasificaciones de Tournefort, John Ray y Linneo, éstas podían mutar y mezclarse entre sí para crear nuevas clases. La concepción fijista, más cercana al creacionismo, se oponía a esta visión de la naturaleza en movimiento.

Así como Velasco rechazaba algunas concepciones aristotélicas o bien las reelaboraba, también consideraba sus propias visiones acerca del entorno natural para nombrarlo. La nomenclatura linneana, tan de moda en la segunda mitad del siglo XVIII, quedaba al margen de la Historia Natural de Quito. Los animales, los vegetales, así como muchos ríos, lagos y lugares geográficos, eran llamados de acuerdo con las denominaciones indígenas, por ejemplo "Atahualpa", "Caculí", "Yutu", "Uqui-huanga" o "Machahuanga". El problema de la nomenclatura era un tema que generaba tensión entre las historias naturales de los jesuitas expulsados del Nuevo Mundo y los filósofos europeos. Mientras los últimos intentaban la creación de un código internacional, los primeros reclamaban la insuficiencia de los sistemas generalizadores para la realidad americana. En la obra de Velasco esta postura adquiría caracteres extremos. Las acotaciones de la Real Academia de Historia no alcanzaban para reubicar el texto en el marco de la ciencia moderna.

Las teorías antiamericanistas sobre la degeneración del Nuevo Mundo, el origen del hombre bajo condiciones inferiores y la imposibilidad de progreso, no sólo apartaban al sujeto americano de una realidad histórica y cultural, sino que además lo marginaban de los planes del Creador. Esto hacía innecesaria la conquista espiritual

${ }^{16}$ El trabajo del jesuita chileno Juan Ignacio Molina es uno de los ejemplo más claros al respecto: "He seguido los pasos del naturalista Sueco, no porque esté yo persuadido de que su sistema sea superior á todos los otros, sino porque veo que en el dia es el mas generalmente seguido; pues á pesar de la grande estimación que profeso a su sabiduría, no puedo dexar de decir que me desagrada en muchos puntos muy esenciales su ingeniosa nomenclatura, y que con mayor gusto habría seguido á Waller ó á Bomare en la mineralogoa, el gran Tournefort en la botánica, y a Brisson en la zoología, porque me parecen mas fáciles y acomodados á la inteligencia común" (Juan Ignacio Molina. Compendio de la Historia Geográfica, Natural y Civil del Reino de Chile. Santiago: Pehuén, 2000, p. XII). 
e injustificable la dominación española. Para responder a esto, Velasco hacía uso de las Sagradas Escrituras para restituir la humanidad del indígena y para dar sentido a la labor de los jesuitas en la América Española. Como señalamos anteriormente, la primera preocupación era demostrar que el origen de los indígenas no era americano, sino asiático: "Todo el que venera la Sagrada Historia, confiesa no haber en toda la tierra especie de cuadrúpedo que no tenga su origen en el Asia, después del General Diluvio" (Velasco, 1977: 170). Por esto, los capítulos 1, 2, 3 y 4 del Libro IV estaban dedicados a esclarecer esos aspectos y a postular teorías sobre cómo el hombre llegó al Nuevo Mundo.

El lugar que ocupaban las Sagradas Escrituras en el pensamiento científico era predominante en Velasco. Si bien hoy en día un lector común relacionaría un texto bíblico con asuntos de fe, a mediados del siglo XVIII la ciencia y la religión no habían tomado caminos distintos y aún actuaba el peso de la tradición cuando era necesario explicar los fenómenos de la naturaleza o la constitución del mundo. Lo que aún resulta más curioso es el modo en que el abate hacía uso de la Historia Sagrada para hacerla coincidir con una visión del tiempo progresista, más cercana al pensamiento ilustrado, incluyendo fechas y lugares para hablar del diluvio y de la supuesta unión de los continentes a través de islotes, o para señalar la pluralidad de lenguas gracias al mito de la torre de Babel.

Por otra parte, el sentimiento de libertad a través del pensamiento, tan propio del humanismo, se abría por completo durante el siglo de la razón y mostraba las fisuras de una visión providencialista de la Historia. Aparentemente este mismo hecho llevaba al jesuita a indagar en otros sistemas de construcción del mundo que si bien integraban la erudición tradicional, también optaban por la experiencia y la observación como primer método de aproximación a la verdad. No se trataba de una contradicción interna, sino más bien de una integración de lo experimentado con las doctrinas antiguas. No obstante, es necesario definir el concepto mismo de experiencia en coherencia con el texto para denotar los aspectos que diferenciaban la Historia narrada por un criollo, de las Historias escritas por los hombres ilustrados o los misioneros.

Durante la Ilustración, la experiencia significaba un acercamiento empírico a los objetos descritos. Según Benjamín "La Ilustración careció de autoridades, no en el sentido de algo a lo cual hay que someterse sin derecho a crítica, sino en el de potencias espirituales que otorguen un gran contenido a la experiencia" (Benjamin, 1991: 76-77). Esta conciencia más elemental del proceso de conocimiento se posicionó no sin dificultad y reparos en el pensamiento de la Compañía de Jesús. La experiencia sensorial, ver, observar y experimentar, debían mediarse por un sentido trascendente que no estaba presente en la filosofía moderna, no por una superficialidad en su planteamiento, sino por una postura defensiva ante las concepciones metafísicas que suponían un peligro para el progreso. Aunque existían diferencias sustanciales entre ambas posturas, lo importante es señalar que la experiencia difería como concepto dependiendo de sus objetivos, y del lugar desde el cual se enunciaba. De ahí que esta noción sufriera un desplazamiento hacia la esfera del mundo 
criollo, sobre todo en la obra de Velasco, quien sistematizaba un saber particular y propio que se diferenciaba del saber de los otros miembros de la compañía de Jesús que habían vivido en misiones, colegios y universidades, pero que no habían nacido bajo el influjo de las culturas indígenas y que, por lo tanto, no compartían ni un sentimiento ni un origen común.

El padre Juan de Velasco construyó la Historia Natural basándose en los mitos y hechos fabulosos venidos de las tradiciones populares. Su obra no era una descripción científica minuciosa de plantas y animales, sino más bien una narración acerca de las cualidades de los seres de la naturaleza y de los aspectos maravillosos que los rodeaban. Su método de investigación estaba basado en las fuentes populares y en la propia experiencia. Para el jesuita, describir una flor, un metal o una fiera, involucraba un conocimiento general de los sucesos y circunstancias que envolvían a ese elemento. Las propiedades curativas de una planta no podían ser descritas sin la intervención de una historia que narrara el origen de esos efectos. Esta esencia mítica en el pensamiento del abate permitía concebir su sistema narrativo como la resignificación de la experiencia en el contexto hispanoamericano. El mismo concepto de verdad objetiva cultivado por la red jesuítica, se desplazaba por el de una verdad americana, es decir, por un proceso enunciativo en el cual el sujeto de la enunciación se insertaba en el discurso como parte del mundo narrado.

En estas intrahistorias, el elemento maravilloso se concebía como real e implicaba un mecanismo de acción específico frente a sus cualidades, por lo tanto, las acciones estaban condicionadas al conocimiento de la tradición indígena, de tal manera que los saberes de la naturaleza le concedían al sujeto narrador una ventaja frente al extranjero ya que su experiencia ontológica posibilitaba ver aquello que un forastero no podría apreciar ni mucho menos entender. Así mismo, podía contar aspectos del mundo americano que sobrepasaban su capacidad explicativa y que se mantenían más allá de la ciencia moderna. La naturaleza del Nuevo Mundo superaba al abate cuando sus sistemas explicativos eran principalmente occidentales. Solo en la medida en que cedía a una tradición anterior a la llegada de los españoles y al impulso de lo fantástico, daba al reino una filiación particular y específica que lo hacía diferente de la potencia europea y por qué no, muchas veces inalcanzable.

Es sabido que en el siglo XVIII el pensamiento mítico no había sido relegado por completo a la categoría de ficción. Algunos hombres de letras aún en esos años dedicaban sus investigaciones al unicornio, por lo tanto, considerar los mitos privativos del pensamiento indígena o americano, es tanto más erróneo como limitado. Lo que sí podemos hacer es indagar en la función que cumplían en el interior del sistema criollo y cómo Velasco se impregnaba de ellos para caracterizar una cultura. Consideramos este aspecto para destacar el lugar que ocupaban los mitos clásicos en el discurso del abate. La integración de la mitología antigua le confería cierta autoridad a su discurso con el fin de particularizar las tierras de Quito y de crear un paisaje dotado de representaciones maravillosas y singulares. En este mismo sentido, se mostraba a sí mismo capaz de afrontar esta nueva realidad en tanto suje- 
to criollo. Aquellas micronarrativas que componían el relato del jesuita reactualizaban los mitos y creencias populares con el objeto de atribuir a la comunidad modelos o fuentes de inspiración que definían y diferenciaban el entorno cultural al que pertenecían. De esta manera la experiencia del sujeto criollo adquiría significado porque formaba parte de la Historia de un pueblo y funcionaba como un subconjunto autónomo al interior de una esfera mundial, mucho más amplia y enriquecedora que los estrechos límites que imponía la conquista española.

En lo que respecta al Reino Racional, todo el capítulo en cuestión revelaba la existencia de un pensamiento mítico para ordenar el mundo. Sin embargo, en este caso no se trataba del mito antiguo, sino del mito moderno en cuanto a la necesidad del hombre de otorgar un origen a un pueblo: una nación sin origen es como si no existiera. Para este caso, la concepción de Velasco es moderna aunque para ello regresara hacia un pasado remoto esbozado en las tradiciones orales y populares de los indígenas. Esta necesidad de Historia era un instrumento de lucha y propaganda política. El deseo de un origen noble y de una Historia antigua, eran parte de las preocupaciones que dominaban al hombre ilustrado. En el mito de origen se encontraba también el deseo de nobleza asociado a un patrón racial. Se buscaba en los antepasados primordiales, los héroes y los nobles, la potencia de los americanos. El jesuita indagaba en la virtud de la raza indígena no para reivindicarla por sí misma sino para reformular su posición de criollo en el mundo. De ahí que las narraciones orales sobre los Quitus y los Scyris fueran aceptadas por Velasco como hechos verdaderos. Con esto, el jesuita otorgaba una justificación histórica, sociopolítica y cultural al territorio que ocupaba la audiencia de Quito y señalaba la continuidad de dicho reino en el grupo de los criollos:

Velasco resultó un adelantado del pensamiento criollo constructor del Estado nacional, al dotar de fundamento histórico a ese proyecto, argumentando su legitimidad, a tiempo que transfería a los criollos la idea de su continuidad [...] Los criollos se asumieron como herederos y continuadores de los Scyris, puesto que eran ellos y no los indios, los sectores con potencialidad para llevar adelante el proyecto. (Valarezo, 2004: 47-48)

El análisis de los aspectos míticos de la narración de Velasco es un trabajo que excede estas páginas. Por ahora hemos querido aportar un panorama general que rescatara ciertos aspectos de la identidad criolla planteados por el jesuita y que nos acercara, a groso modo, al proyecto cultural e histórico al que aludía la Historia del Reino de Quito de la América Meridional.

\section{Conclusiones}

La Historia del Reino de Quito de la América Meridional, es una obra que se enmarcaba en las producciones dieciochescas de los jesuitas expulsados de los terri- 
torios del Nuevo Mundo. Aunque su función inicial era crear una respuesta a las teorías antiamericanistas, los modos que adquiría la narración sobrepasaban sus objetivos originales. La Historia Natural desafiaba los cánones de la época y proponía un conocimiento desde la perspectiva del otro criollo que superaba el saber occidentalista europeo y suponía una construcción cultural, social e histórica para el Reino de Quito. Este proceso se iniciaba con la reivindicación de la naturaleza americana y con su inclusión en el plan de la Creación. Para ello, Velasco postulaba una serie de ideas acerca del poblamiento de las tierras y proponía un origen para el hombre indígena unido a la Historia ortodoxa. Cuando el entorno americano y el hombre parecían estar a salvo en el marco del plan de Dios, Velasco planteaba un origen para Quito que restituía su calidad de Reino con una formación histórica independiente y con una cultura particular, diferenciada de sus vecinos incas, pero no del todo desligada de ellos. Diferenciada porque buscaba establecerse una identidad y ligada porque se apoyaba en una cultura reconocida por los españoles y el resto de los europeos. Este plan era el producto de una conciencia criolla que buscaba definirse en sus límites geográficos y darse a conocer como una entidad histórica y cultural determinada. El papel que correspondía a los criollos en el mundo colonial no alcanzaba las expectativas de éstos, generando el descontento y el rencor. A este hecho se sumaban las teorías "científicas" que lo marginaban del mundo y sobre todo los relegaba a categorías inferiores desde las cuales no podían acceder a un poder colonial que ellos consideraban legítimo por heredad, tanto de la conquista como de la tradición indígena.

Por este motivo, pese a que la Historia Natural de Velasco se insertaba en la tradición de las Historias escritas en el Nuevo Mundo por la Compañía de Jesús, su narración contribuyó al establecimiento de una identidad criolla en el Reino de Quito. Así, la idea de Historia para el abate constituía una resignificación de la experiencia como método de conocimiento y aproximación al mundo del hombre. $\mathrm{Su}$ saber estaba mediado por la implicación del sujeto en el espacio narrado, por lo tanto, su experiencia no era la observación y el análisis, era la vivencia criolla, la percepción desde una cosmovisión propia, definida principalmente por los mitos y las tradiciones de los pueblos indígenas de la zona. Este hecho llevaba a recuperar los relatos de los pueblos originarios para situarlos en la esfera de lo real. El pensamiento mítico de Velasco sustituía el concepto de verdad sobre el cual se habían fundado las Historias de los jesuitas en América. Ya no se trataba de la verdad en un sentido moral y religioso, sino de una verdad propia, particular, idiosincrática: una verdad criolla. Por este motivo, los hechos fantásticos y maravillosos eran narrados como una realidad más del Reino de Quito. El abate no discriminaba entre lo que parecía real y lo que no lo parecía, su relato recogía todos los elementos de la cultura y con ello expresaba los rasgos de una identidad cuyos orígenes se encontraban en la nación de los Quitus. Ya que la preocupación del autor era desplazarse de los márgenes hacia los centros de poder, sus estrategias no incluían otros sectores que no fueran los del grupo criollo. El inicio de una genealogía quítense con el 
estatus de Reino no tenía dentro de sus fines reivindicar a los indígenas sometidos y avasallados por la sociedad colonial. Tampoco eliminaba el concepto de raza bajo el cual se justificaban los abusos hacia los más desfavorecidos (indígenas, negros, mulatos, zambos). Principalmente restituía un origen noble a la nación para así proclamar a los criollos sucesores e intermediarios privilegiados entre la razón occidental y el mundo americano.

Este trabajo constituye un acercamiento inicial al problema de estudio y de ninguna manera agota el tema en cuestión. Su función es ofrecer un bosquejo de la Historia Natural de Juan de Velasco, considerando la tradición a la cual pertenecía, para luego abarcar los aspectos de la diferencia que proponía el sujeto criollo desde una posición que negociaba con los centros de poder un saber sobre Hispanoamérica. Resta señalar que el interés de esta investigación radica en la búsqueda de los mecanismos a través de los cuales los grupos criollos generaban su propia identidad, y cómo este proceso deja muchas veces de lado una realidad tangible asociada a los grupos más marginados. Estos discursos, que más tarde conformarían parte del imaginario nacional, desligaban de sus preocupaciones las problemáticas de los grupos menos favorecidos. La aproximación a la mentalidad de un intelectual perteneciente al período en que se está gestando la futura conciencia nacional de Ecuador nos proporciona, además, una perspectiva histórica que remite a circunstancias actuales, a problemáticas no resueltas que sólo es posible comprender a partir de ese momento fundacional.

\section{BIBLIOGRAFÍA}

ARISTÓTELES.

1987 Acerca de la generación y la corrupción; Tratados breves de historia natural. Madrid: Gredos.

ARREGI, Federico.

1993 "El debate del Nuevo Mundo", en Pizarro, Ana. América Latina: Palabra, literatura e cultura. Vol. 2. Sao Paulo: Memorial.

BARBA, Esteve.

1965 Cultura Virreinal. Madrid: Salvat.

BATLLORI, Miguel.

1995 El abate Viscardo. Historia y mito de la intervención de los jesuitas en la independencia de Hispanoamérica. Madrid: Mapfre.

BENJAMIN, Walter.

1991 "El narrador", en Para una crítica de la violencia y otros ensayos. Madrid: Taurus.

BRADING, David.

1991 El Orbe Indiano. De la monarquía católica a la República criolla. México: FCE. 
ELIADE, Mircea.

2000 Aspectos del Mito. Barcelona: Paidós.

FOUCAULT, Michel.

1999 Las palabras y las cosas. España: Siglo XXI Editores.

GENETTE, Gerard.

1989 Palimpsestos. Madrid: Taurus.

GERBI, Antonello.

1982 La Disputa del Nuevo Mundo. México: FCE.

KOHUT, Karl y Sonia ROSE (eds.).

2006 La formación de la cultura virreinal. El siglo XVIII. Madrid: Iberoamericana

MARZAL, Manuel y Luis BACIGALUPO.

2007 Los jesuitas en Iberoamérica. Lima: Fondo Editorial de la Pontificia Universidad Católica del Perú.

MAZzotTI, José Antonio.

2000 Agencias Criollas. La ambigüedad colonial de las letras hispanoamericanas. Pittsburg: Biblioteca de América.

MILLONES, Luis y Domingo LEDESMA.

2005 El saber de los jesuitas, historias naturales y el Nuevo Mundo. Madrid: Textos y Estudios de la Independencia.

MOLINA, Juan Ignacio.

2000 Compendio de la Historia Geográfica, Natural y Civil del Reino de Chile. Santiago de Chile: Pehuén Editores.

NAVIA MÉNEZ-BONITO, Silvia.

2004 "Reivindicación del reino de Quito en la Historia del Reino de Quito de Juan de Velasco", en Sosa, Buchholz, Ximena y F. Waters, William, (comp.). Estudios Ecuatorianos, un aporte a la discusión. Ponencias Escogidas del II Encuentro de la Sección de Estudios Ecuatorianos LASA. Quito: Abya-Yala.

2005 "Las historias naturales de Francisco Javier Clavijero, Juan Ignacio Molina y Juan de Velasco", en Millones, Luis y Domingo Ledesma. El saber de los jesuitas, Historias Naturales y el Nuevo Mundo. Madrid: Iberoamericana.

PAREJA DíEz CASENo, Alfredo.

1981 Historia del Reino de Quito de la América Meridional. Caracas: Biblioteca Ayacucho.

PICÓN SALAS, Mariano.

1965 De la Conquista a la Independencia. México: FCE.

PINO, Fermín del.

2000 "La historia natural y moral de las indias como género: orden y génesis literaria de la obra de Acosta" 
SANTOS, Ángel.

1992 Los jesuitas en América. Madrid: Editorial Mapfre.

TORALES PACHECO, María Cristina.

2007 "Los jesuitas, la modernidad y el espacio público ilustrado", en Los jesuitas y la modernidad en Iberoamérica. Lima: Fondo Editorial de la Pontificia Universidad Católica del Perú.

VALAREZO, Galo Ramón y Víctor Hugo TORRES DÁVILA.

2004 El desarrollo local en el Ecuador. Quito: Abya-Yala.

VELASCO, Juan.

1977 Historia del Reino de Quito de la América Meridional. Quito: Casa de la Cultura Ecuatoriana.

WILLINGHAM, Eileen.

2005 "Locating Utopia: Promise and Patria in Juan de Velasco's Historia del Reino de Quito", en Millones, Luis y Domingo Ledesma. El saber de los jesuitas, historias naturales y el Nuevo Mundo. Madrid: Textos y Estudios de la Independencia. 